Research Paper

\title{
Effect of Exercise Training on Skeletal Muscle SIRT1 and PGC-1 a Expression Levels in Rats of Different Age
}

\author{
Chi-Chang Huang $1^{*}$, Ting Wang ${ }^{2}$, Yu-Tang Tung $1^{*}$ and Wan-Teng Lin ${ }^{凶}$ \\ 1. Graduate Institute of Sports Science, College of Exercise and Health Sciences, National Taiwan Sport University, Taoyuan 33301, Taiwan; \\ 2. Department of Hospitality Management, College of Agriculture, Tunghai University, Taichung 40704, Taiwan. \\ "These authors contributed equally to this work.
}

$\square$ Corresponding author: Wan-Teng Lin, Ph.D., Associate Professor, Department of Hospitality Management, Tunghai University, No.181, Sec. 3, Taichung Port Rd., Situn District, Taichung City 40704, Taiwan. Tel.: +886-4-2359-0121 (ext. 37709); fax: +886-4-2350-6053 E-mail: 040770@thu.edu.tw.

( ) Ivyspring International Publisher. Reproduction is permitted for personal, noncommercial use, provided that the article is in whole, unmodified, and properly cited. See http://ivyspring.com/terms for terms and conditions.

Received: 2015.12.02; Accepted: 2016.02.24; Published: 2016.03.16

\begin{abstract}
The protein deacetylase sirtuin 1 (SIRT1) and activate peroxisome proliferator-activated receptor- $\gamma$ coactivator-1 $\alpha$ (PGC- $1 \alpha$ ) pathway drives the muscular fiber-type switching, and can directly regulate the biophysiological functions of skeletal muscle. To investigate whether 12-week swimming exercise training modulates the SIRT1/PGC- $1 \alpha$ pathway associated proteins expression in rats of different age. Male 3-month-old (3M), 12-month-old (12M) and 18-month-old (18M) Sprague-Dawley rats were used and assigned to sedentary control (C) or 12-week swimming exercise training $(\mathrm{E})$ and divided into six groups: $3 \mathrm{MC}(n=8), 12 \mathrm{MC}(n=6), 18 \mathrm{MC}(n=8), 3 \mathrm{ME}(n$ $=8), 12 \mathrm{ME}(n=5)$ and 18ME $(n=6)$. Body weight, muscle weight, epididymal fat mass and muscle morphology were performed at the end of the experiment. The protein levels of SIRT1, PGC-1 $\alpha$, AMPK and FOXO3a in the gastrocnemius and soleus muscles were examined. The SIRT1, PGC-1 $\alpha$ and AMPK levels in the gastrocnemius and soleus muscles were up-regulated in the three exercise training groups than three control groups. The FOXO3a level in the 12ME group significantly increased in the gastrocnemius muscles than 12MC group, but significantly decreased in the soleus muscles. In 3-, 12- and 18-month-old rats with and without exercise, there was a significant main effect of exercise on PGC-1 $\alpha$, AMPK and FOXO3a in the gastrocnemius muscles, and SIRT1, PGC- $1 \alpha$ and AMPK in the soleus muscles. Our result suggests that swimming training can regulate the SIRT1/PGC-1 $\alpha$, AMPK and FOXO3a proteins expression of the soleus muscles in aged rats.
\end{abstract}

Key words: exercise training, aging, skeletal muscle, SIRT1, PGC-1 $\alpha$.

\section{Introduction}

Physical exercise enhances or maintains physical fitness and health. Regular physical exercise helps to improve human physiological function $[1,2]$, and prevent the metabolic syndrome, heart disease, cardiovascular disease, hypertension, Type 2 diabetes, obesity and so on [3, 4]. Childhood obesity is a growing global problem, and physical exercise may help decrease some of the effects of childhood and adult obesity. It has been believed that exercise is an efficient non-pharmacological intervention for human health.

Physical exercises are generally grouped into aerobic exercise, anaerobic exercise and flexibility exercise. Swimming exercise training is an aerobic exercise that uses large-muscle groups and causes your body to use more oxygen than it would while resting. Exercise demands a greater supply of energy [5]. Different types of exercises elicit varied responses from various substrates including glucose, lactate and pyruvate in the blood that may be due to changes in the effect of stress imposed on the individual organs $[6,7]$. Swimming has been considered as a suitable model of endurance exercise training [8]. Ravi Kiran et al. [9] showed swimming exercise training significantly increased superoxide dismutase (Mn-SOD), and reduced lipid peroxidation products, 
malondialdehyde (MDA) and lipofuscin in the left and right ventricles.

SIRT1 is an enzyme that deacetylates FOXO3a and NF-kB [10-12]. FOXO3a and NF-KB deacetylation causes their transcription to fail and inhibits the downstream regulation of cell death by inflammation proteins [13]. Thus, SIRT1 activation could promote cell survival. Zarzuelo et al. [14] showed that the appropriate long-term exercise training can protect the heart through SIRT1 activation and reducing ROS. Ferrer et al. [15] reported that the SIRT3 and PGC-1a increases in white blood cells to activate the antioxidant response after intense swimming. In addition, SIRT3 and PGC-1a in human skeletal muscle decreased with age and correlate with a sedentary proteomic profile found in people with decreased metabolic output [16]. With exercise, however, Palacios et al. [17] observed that the effect is reversed.

The purpose of the present study was to examine the effects of swim exercise training at $40 \mathrm{~min} / \mathrm{d}$ for 12 weeks on SIRT1, PGC-1a, AMPK and FOXO3a in adult (6-month-old), middle-aged (12-month-old) and old-aged rats (18-month-old).

\section{Materials and methods}

\section{Animals and experiment design}

Specific pathogen-free female Sprague Dawley (SD) rats were purchased from BioLASCO (A Charles River Licensee Corp., Yi-Lan, Taiwan). All animals were fed a chow diet (No. 5001; PMI Nutrition International, Brentwood, MO, USA), distilled water ad libitum, housed at room temperature $\left(23 \pm 2^{\circ} \mathrm{C}\right)$ and humidity-controlled $(70 \pm 10 \%)$ with a 12 -h light/12-h dark cycle. Fig. 1 denotes the categorization of rats into groups and subgroups. In brief, rats were randomly assigned to one of three groups i.e. 3-, 12and 18-month-old, and two sub groups with or without swim exercise training intervention. Thus, SD rats were assigned into sedentary control (C) or a 12-week swimming exercise training (E), and divided into six groups: (1) 3-month-old rats without swim exercise training (3MC; $n=8$ ); (2) 3-month-old rats with swim exercise training (3ME; $n=8)$; (3) 12-month-old rats without swim exercise training (12MC; $n=6)$; (4) 12-month-old rats with swim exercise training (12ME; $n=5)$; (5) 18-month-old rats without swim exercise training (18MC; $n=8)$; (6) 18-month-old rats with swim exercise training (18ME; $n=6)$. Animals were anesthetized with Zoletil/Xylazine and sacrificed after 12-week swimming exercise training. Body weight, muscle weight, epididymal fat mass and muscle morphology were performed at the end of the experiment. The gastrocnemius and soleus muscles were carefully harvested, rinsed in ice-cold normal saline, blotted dry and stored at $-80^{\circ} \mathrm{C}$ for further analysis. All animal experimental protocols were approved by the Institutional Animal Care and Use Committee (IACUC) of Tunghai University, and the study conformed to the guidelines of the protocol IACUC-98-27 approved by the IACUC ethics committee.

\section{Exercise training program}

Swim exercise training was similar to earlier protocols with minor modifications [9]. In brief, rats were made to exercise in groups of three in a plastic tank (diameter: $48 \mathrm{~cm}$ ) filled with water to a height of $50 \mathrm{~cm}$ at $35 \pm 1^{\circ} \mathrm{C}$. Animals were trained daily between AM 10:00 and PM 12:30. The pre-training period lasted for three-weeks (the first weeks lasted only 10 min, the second weeks lasted only $20 \mathrm{~min}$, and the third weeks lasted only $30 \mathrm{~min}$ ), and the animals were exercised in $40 \mathrm{~min} /$ day, 5 days/week for 4-12 weeks (Fig. 1B). At the completion of exercise, rats were towel-dried and returned to their respective cages. No deaths occurred during or after exercise in any groups. Sedentary control group of rats were confined to stand in groups of three in a plastic tank (diameter: $48 \mathrm{~cm}$ ) filled with water to a height of $5 \mathrm{~cm}$ at $35 \pm 1^{\circ} \mathrm{C}$. The body weight of all groups was monitored recorded weekly.

\section{Gross and histological evaluation of the gastrocnemius and soleus muscles}

The gastrocnemius and soleus muscles were fixed in $10 \%$ formalin, embedded in paraffin and cut into $4-\mu \mathrm{m}$ thick slices as per our previous study. Tissue sections were stained with Hematoxylin and Eosin (H\&E), and examined using a light microscope equipped with a CCD camera (Olympus BX50; Olympus Co., Ltd., Tokyo, Japan). The total muscle area of each section was highlighted and the total number of pixels was recorded.

\section{Western blot analysis}

Expressions of the gastrocnemius and soleus muscle proteins were measured by western blot. The gastrocnemius and soleus muscles were homogenized in $500 \mu \mathrm{l}$ of homogenization buffer $(5 \mathrm{mM}$ Tris- $\mathrm{HCl}$ $\mathrm{pH} 7.4,0.15 \mathrm{M} \mathrm{NaCl}, 1 \% \mathrm{NP} 40,0.25 \%$ Sodium deoxycholate, $5 \mathrm{mM}$ EDTA, and $1 \mathrm{mM}$ ethylene glycol-bis(2-aminoethyl-ether)-N, N, N, N-tetraacetic acid). The homogenates were centrifuged at 13,200 $g$ for 40 minutes at $4^{\circ} \mathrm{C}$. Protein $(50 \mu \mathrm{g})$ was then separated by SDS-PAGE in $8 \%$ polyacrylamide and electrotransferred to polyvinylidene difluoride membranes. The membranes were incubated in blocking solution ( $5 \%$ milk) at room temperature for 2 
hours. The membranes were then incubated with primary antibody including SIRT1 (sc-74465, Santa Cruz, USA), PGC-1a (\#516557, Calbiochem, USA), FOXO3a (\# 2497, Cell Signaling, USA), AMPK (sc-33524, Santa Cruz, USA), and a-tubulin (sc-74465, Santa Cruz, USA) overnight at $4^{\circ} \mathrm{C}$. After washing, the membranes were incubated with a goat anti-rabbit (Santa Cruz, USA) or goat anti-mouse IgG (Santa Cruz, USA) peroxidase-conjugated secondary antibody directed against the primary antibody. The membranes were developed by an enhanced chemiluminescence western blot detection system.

\section{Statistical analysis}

Data were expressed as mean \pm SEM. Results were analyzed by one-way analysis of variance (ANOVA, Scheffe's method). A value of $P<0.05$ was considered to indicate statistical significance.

(a)
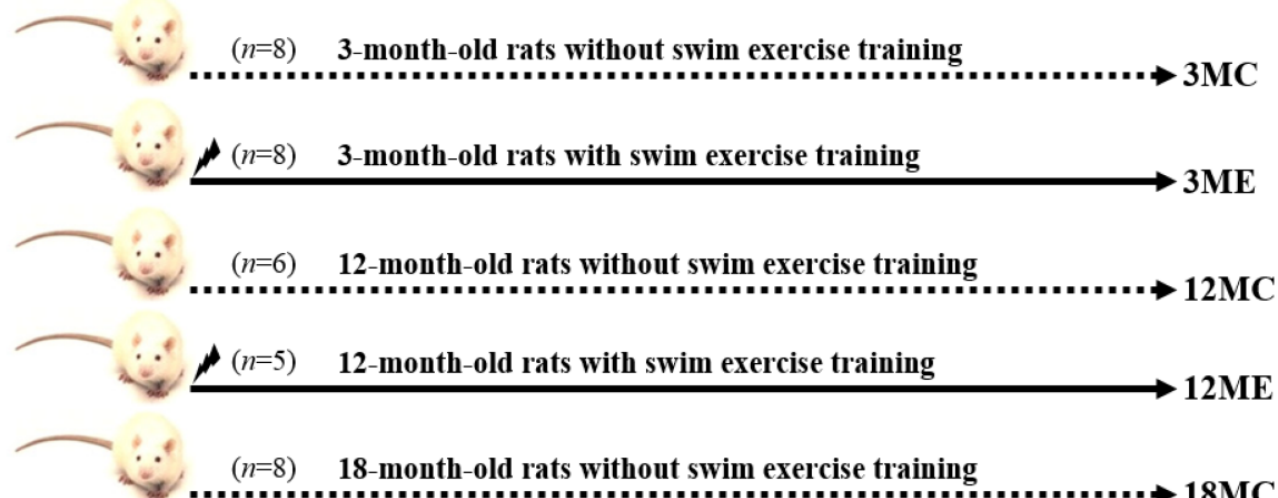

18-month-old rats with swim exercise training

$18 \mathrm{ME}$

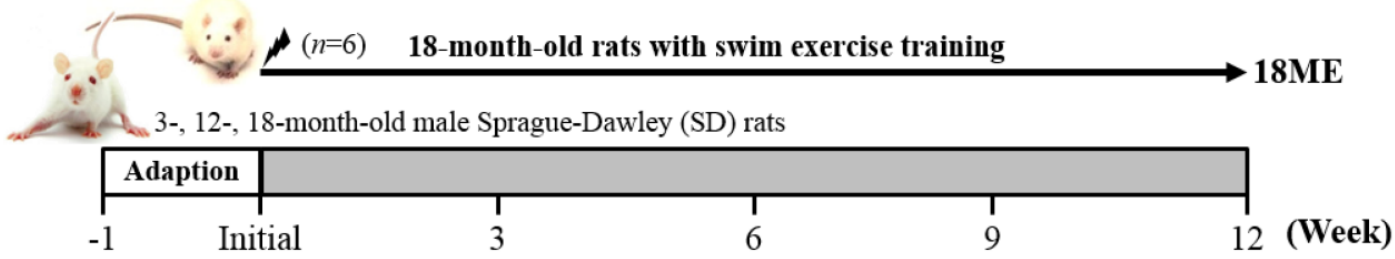

(b)

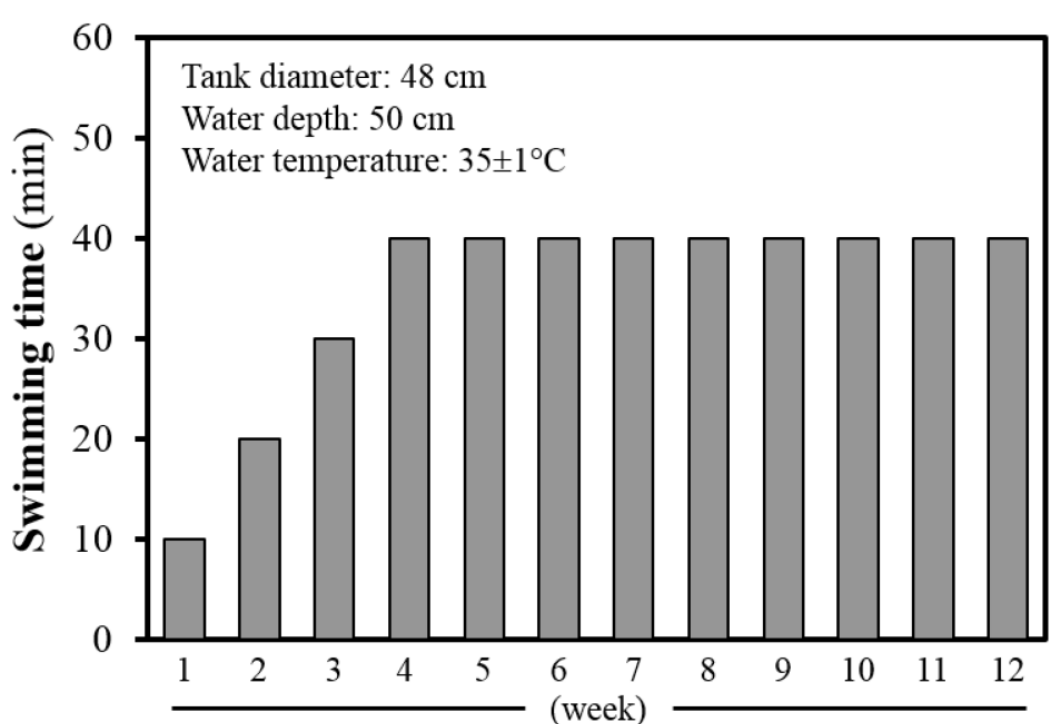

Figure 1. Experimental design (a) and protocol for 12-wk swim exercise training (b). Male 3-month-old (3M), 12-month-old (12M) and 18-month-old (18M) Sprague-Dawley rats were used for this study, assigned to sedentary control $(C)$ or 12 -week swimming exercise training (E) and divided into six groups: which were respectively designated the $3 \mathrm{MC}(n=8), 12 \mathrm{MC}(n=6), 18 \mathrm{MC}(n=8), 3 \mathrm{ME}(n=8), 12 \mathrm{ME}(n=5)$ and $18 \mathrm{ME}(n=6)$. The pre-training period lasted for three-weeks (the first weeks lasted only $10 \mathrm{~min}$, the second weeks lasted only $20 \mathrm{~min}$, and the third weeks lasted only $30 \mathrm{~min}$ ), and the rats were exercised in $40 \mathrm{~min} / \mathrm{day}, 5$ days/week for 4-12 weeks. 
(a)

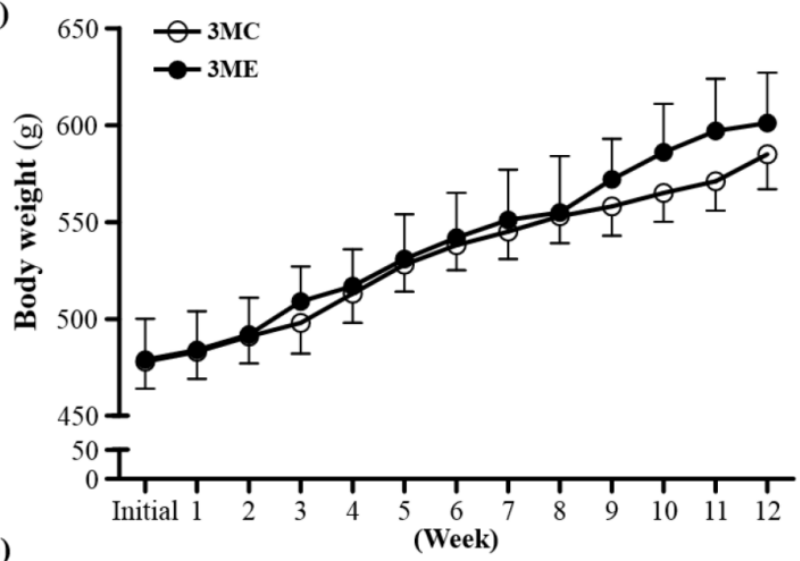

(b)

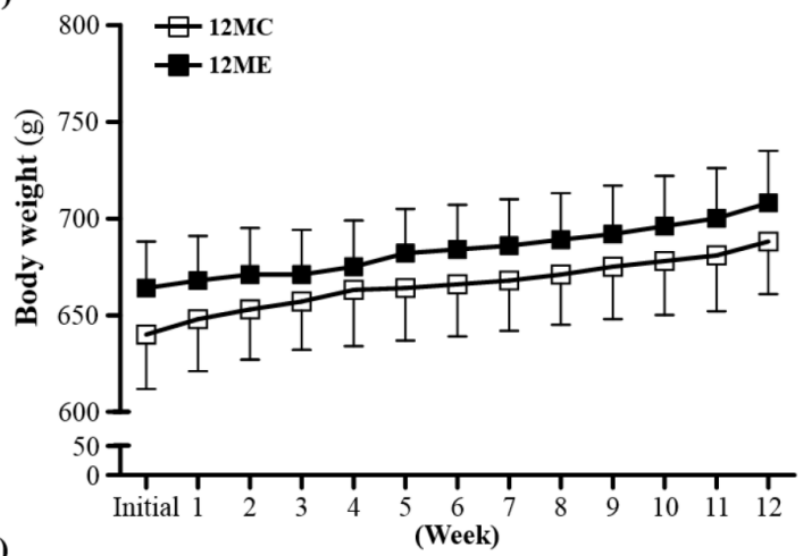

(c)

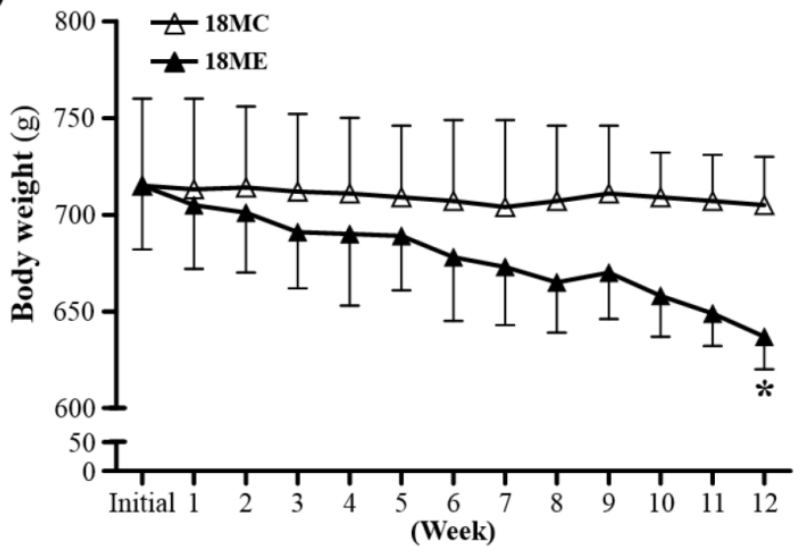

Figure 2. Body weights over the course of 12 weeks. 3MC; male 3-month-old $\mathrm{SD}$ rats without swimming exercise training, 3ME; male 3-month-old SD rats with swimming exercise training, 12MC; male 12-month-old SD rats without swimming exercise training, 12ME; male 12-month-old SD rats with swimming exercise training, 18MC; male 18-month-old SD rats without swimming exercise training, 18ME; male 18-month-old SD rats with swimming exercise training. Data are mean \pm SEM. * indicated significant difference at $P<0.05$ by one-way ANOVA.

\section{Results}

\section{Effect of exercise training on body weight}

The rats of the two experimental groups at the same age had the similar initial body weights. To examine whether swim exercise training could increase or decrease body weight was recorded weekly (Fig. 2). After swim exercise training for 40 $\min / \mathrm{d}, 5$ days/week, for 12 weeks, there was no difference found in body weight between 3MC group and $3 \mathrm{ME}$ group, or $12 \mathrm{MC}$ group and $12 \mathrm{ME}$ group. In addition, it is interesting that the 18-month-old rats after swim exercise training showed a significant decrease in body weight by $9.6 \%$ (637 $\pm 17 \mathrm{~g})$ relative to the rats without swim exercise training $(705 \pm 25 \mathrm{~g})$ $(P=0.0486)$. Numerous studies have shown that male rats subjected to a program of regularly performed endurance exercise gain weight more slowly and have significantly lower final body weights than freely eating sedentary controls [18].

\section{Effect of exercise training on epididymal fat pad}

The epididymal fat pad (EFP) weights at the end of the study were shown in Table 1. EFP mass was slightly lowered in 3-, 12- or 18-month-old rats for swim exercise training compared to 3-, 12- or 18- rats without swim exercise training by $2.3 \%, 15.7 \%$ or $43.8 \%(P=0.0868)$, respectively. In addition, the relative weight of EFP was slightly decreased for swim exercise training than the rats without swim exercise training. In early life of rats, the fat accumulates in EFP as a result of an increase in cell number and cell size [19, 20]. At approximately 15-week-old, cell number becomes fixed in this depot, and only cell size changes with further increases in adiposity $[19,20]$. These results showed that exercise caused a reduction of EFP in 18-month-old and revealed that exercise retards the rate at which adipose tissue cells accumulate or enlarge, or both.

\section{Effect of exercise training on muscles}

The mass of the gastrocnemius muscles was no significant difference in $3 \mathrm{MC}$ group and $3 \mathrm{ME}$ group, $12 \mathrm{MC}$ group and $12 \mathrm{ME}$ group, or $18 \mathrm{MC}$ group and 18ME group (Table 1). The representative pictures of the gastrocnemius muscle fibers in each group were shown in Fig. 3. In the swim exercise training groups, there were increased in the gastrocnemius muscle length and area when compared with those without swim exercise training. The fiber length of the gastrocnemius muscles was significantly increased by $23 \%, 22 \%$ and $31 \%$, respectively, in the $3 \mathrm{ME}$ group $(66.1 \pm 1.4 \mu \mathrm{m}), 12 \mathrm{ME}$ group $(69.0 \pm 1.3 \mu \mathrm{m})$ and $18 \mathrm{ME}$ group $(67.0 \pm 1.5 \mu \mathrm{m})$ when compared with $3 \mathrm{MC}$ group $(53.7 \pm 1.5 \mu \mathrm{m}), 12 \mathrm{MC}$ group $(56.6 \pm 1.4 \mu \mathrm{m})$ and 18MC group $(51.3 \pm 0.8 \mu \mathrm{m})(P<0.05)$. And the area of the gastrocnemius muscles was significantly increased by $40 \%, 44 \%$ and $86 \%$, respectively, in the 3ME group $\left(21903 \pm 827 \mu^{2}\right)$, 12ME group (24164 \pm $771{\left.\mu \mathrm{m}^{2}\right)}^{2}$ and 18ME group $\left(23726 \pm 2282 \mu \mathrm{m}^{2}\right)$ when compared with $3 \mathrm{MC}$ group $\left(15643 \pm 664 \mu^{2}\right), 12 \mathrm{MC}$ group $\left(16740 \pm 720 \mu^{2}\right)$ and 18MC group $(12760 \pm 360$ 
$\left.\mu^{2}\right)(P<0.05)$. In this study, an obvious increase in fiber size of the gastrocnemius muscles in the swim exercise training groups was observed.

The mass of the soleus muscles were no significant difference in the $3 \mathrm{MC}, 3 \mathrm{ME}, 12 \mathrm{MC}, 12 \mathrm{ME}$, $18 \mathrm{MC}$ and $18 \mathrm{ME}$ groups (Table 1), but the soleus muscle length and area were increased in the swim exercise training groups when compared with those without swim exercise training (Fig. 4). The fiber length of the soleus muscles was significantly increased by $8 \%, 32 \%$ and $13 \%$, respectively, in the $3 \mathrm{ME}$ group $(55.3 \pm 0.9 \mu \mathrm{m}), 12 \mathrm{ME}$ group $(69.2 \pm 1.5$ $\mu \mathrm{m})$ and 18ME group $(71.4 \pm 1.2 \mu \mathrm{m})$ when compared with 3MC group $(51.3 \pm 0.8 \mu \mathrm{m}), 12 \mathrm{MC}$ group $(52.4 \pm$ $0.9 \mu \mathrm{m})$ and $18 \mathrm{MC}$ group (63.2 \pm $1.4 \mu \mathrm{m})(P<0.05)$. And the area of $\mathrm{s}$ the soleus muscles was

Figure 3. Effect of exercise training in the gastrocnemius muscles. a; the hematoxylin-eosin (H\&E) staining of histologically sectioned the gastrocnemius muscles. b; the fiber length of the gastrocnemius muscles. c; the fiber area of the gastrocnemius muscles. 3MC; male 3-month-old SD rats without swimming exercise training, $3 \mathrm{ME}$; male 3-month-old SD rats with swimming exercise training, 12MC; male 12-month-old SD rats without swimming exercise training, 12ME; male 12-month-old SD rats with swimming exercise training, 18MC; male 18-month-old SD rats without swimming exercise training, 18ME; male 18-month-old SD rats with swimming exercise training. Data are mean \pm SEM. Different letters indicated significant difference at $P<0.05$ by one-way ANOVA.

(a)
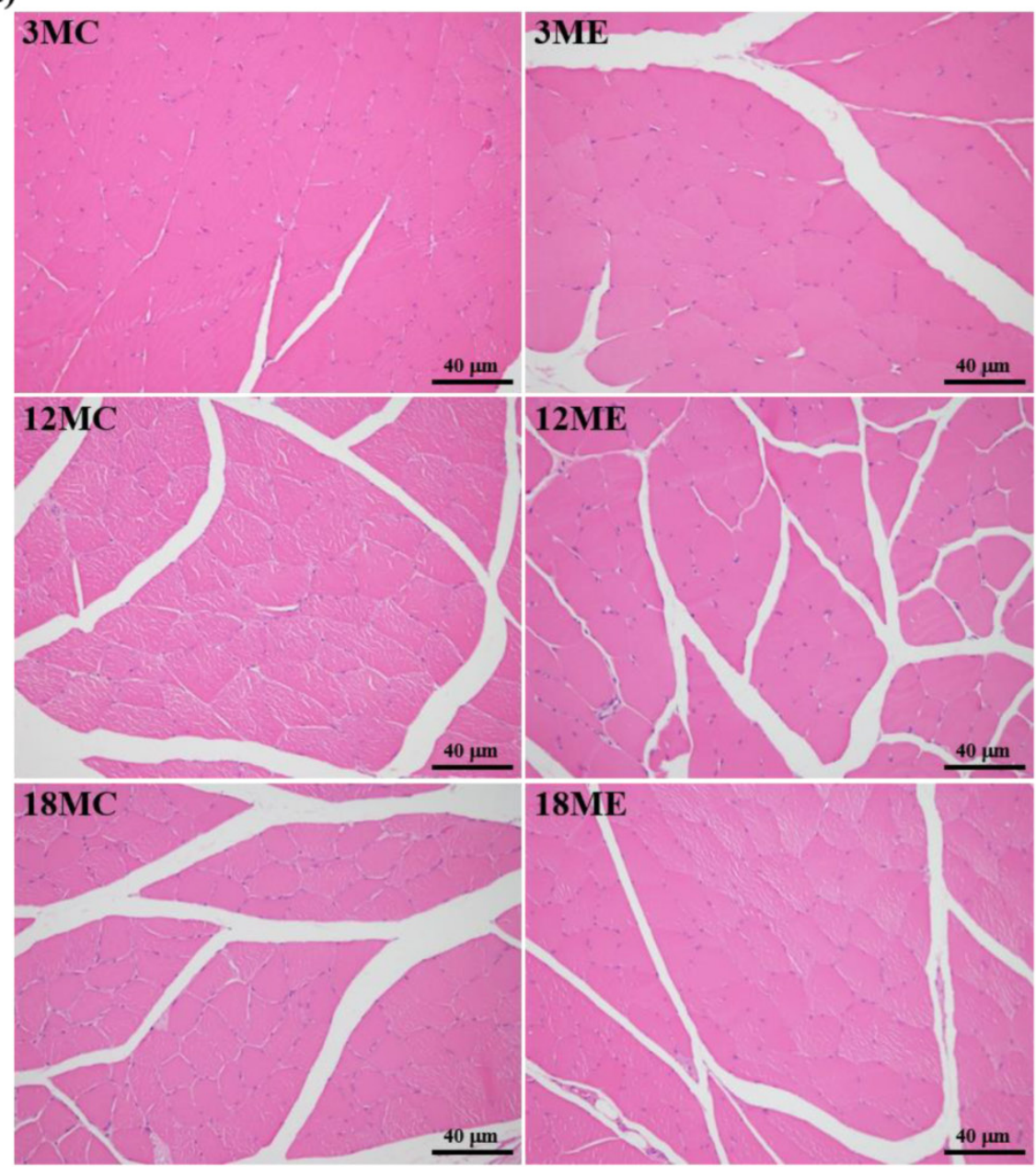

(b)
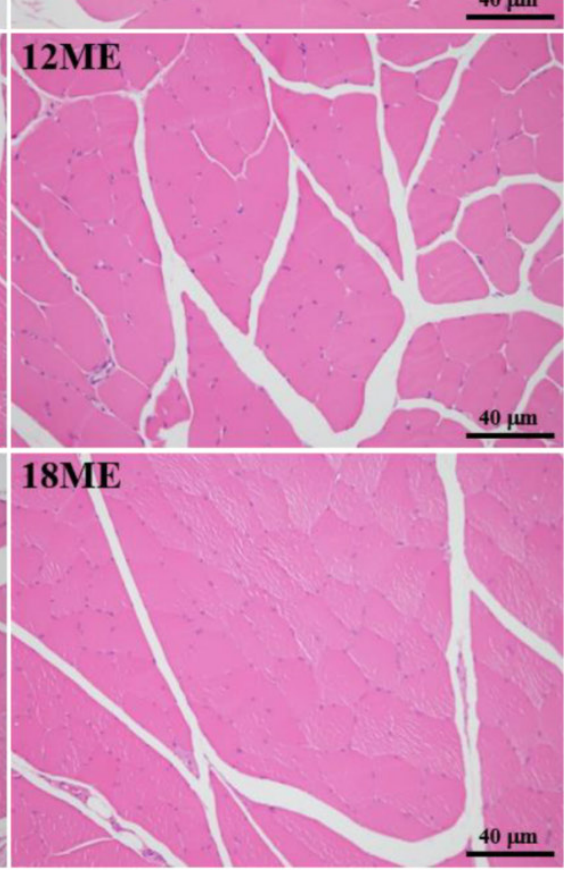

(c)
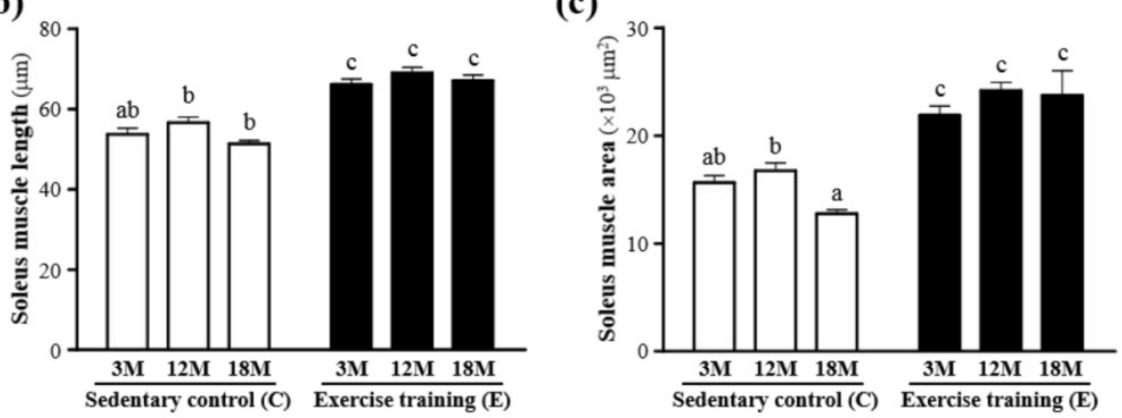
Table 1. General characteristics of the experimental groups

\begin{tabular}{llllll}
\hline Characteristic & $3 \mathrm{MC}$ & $3 \mathrm{ME}$ & $12 \mathrm{MC}$ & $12 \mathrm{ME}$ & $18 \mathrm{MC}$ \\
\hline Initial BW (g) & $478 \pm 14$ & $479 \pm 21$ & $640 \pm 28$ & $664 \pm 24$ & $715 \pm 45$ \\
Final BW (g) & $585 \pm 18$ & $601 \pm 26$ & $688 \pm 27$ & $708 \pm 27$ & $705 \pm 25$ \\
Gastrocnemius (g) & $2.82 \pm 0.18$ & $2.93 \pm 0.10$ & $2.67 \pm 0.15$ & $2.44 \pm 0.09$ & $2.79 \pm 0.14$ \\
Soleus (g) & $0.25 \pm 0.03$ & $0.22 \pm 0.01$ & $0.26 \pm 0.03$ & $0.27 \pm 0.03$ & $0.24 \pm 0.01$ \\
EFP (g) & $4.69 \pm 0.62$ & $4.80 \pm 0.66$ & $5.62 \pm 0.67$ & $4.74 \pm 0.42$ & $8.06 \pm 1.69$ \\
Relative EFP (\%) & $0.80 \pm 0.10$ & $0.78 \pm 0.09$ & $0.82 \pm 0.09$ & $0.67 \pm 0.05$ & $0.25 \pm 0.01$ \\
\hline
\end{tabular}

EFP, epididymal fat pad; Relative EFP (\%), epididymal fat pad weight/body weight $\times 100 \%$.

Data are mean \pm SEM. *, differ significantly at $P<0.05$ by Student's $t$ Test between same age in the same line.

(a)
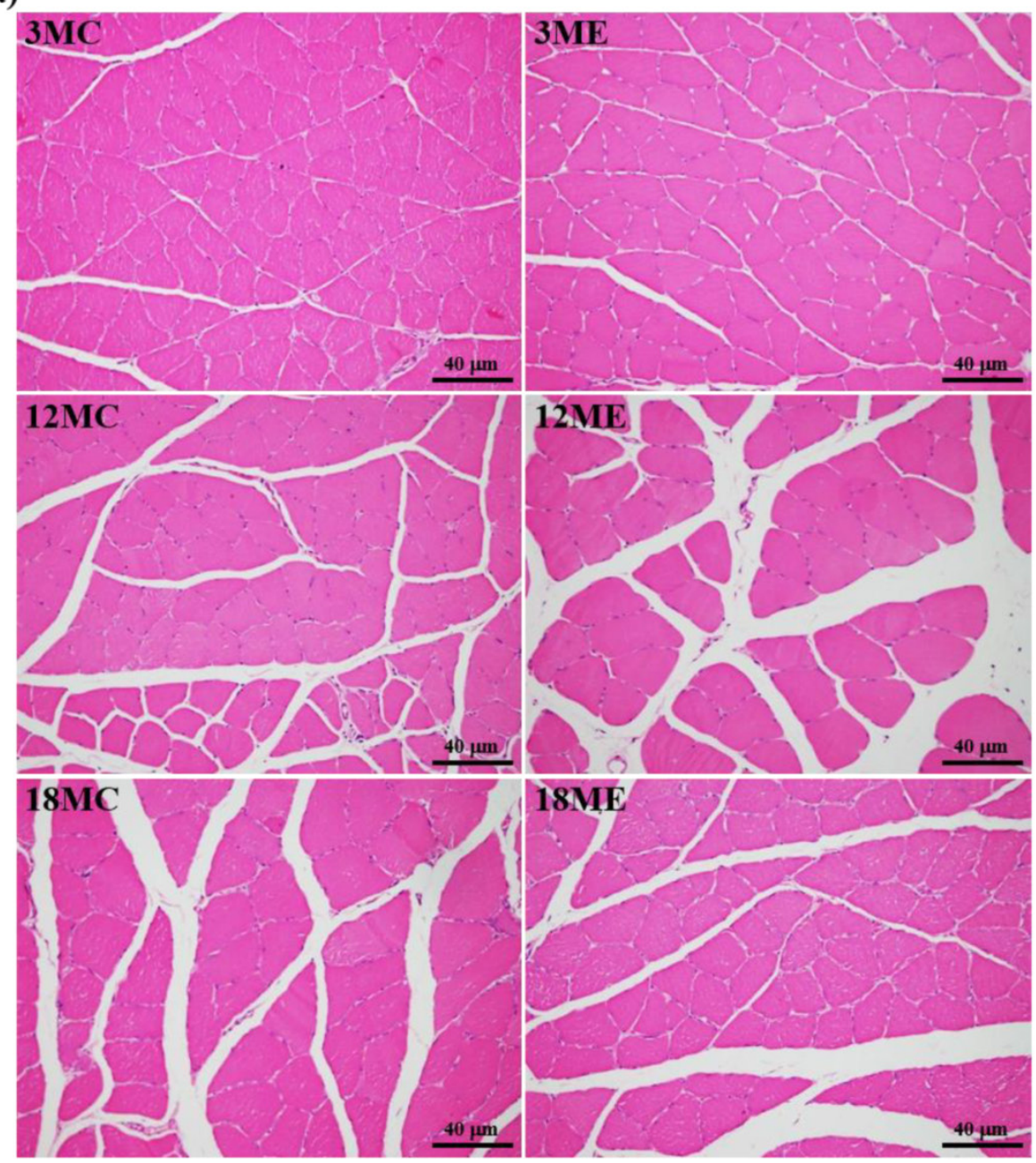

(b)

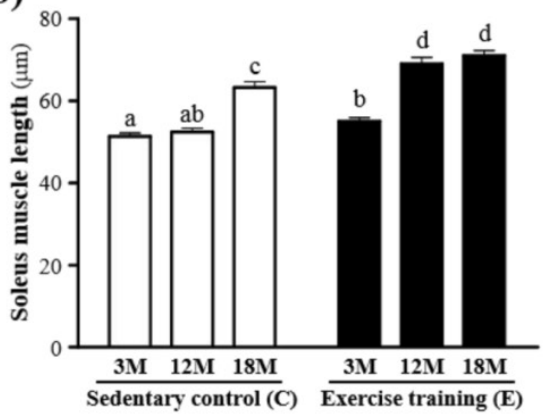

(c)

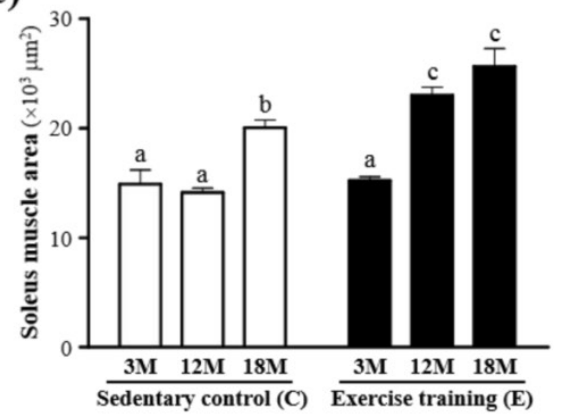

Figure 4. Effect of exercise training in the soleus muscles. $\mathbf{a}$; the hematoxylin-eosin (H\&E) staining of histologically sectioned the soleus muscles. b; the fiber length of the soleus muscles. c; the fiber area of the soleus muscles. 3MC; male 3-month-old SD rats without swimming exercise training, 3ME; male 3-month-old SD rats with swimming exercise training, 12MC; male 12-month-old SD rats without swimming exercise training, 12ME; male 12-month-old SD rats with swimming exercise training, 18MC; male 18-month-old SD rats without swimming exercise training, 18ME; male 18-month-old SD rats with swimming exercise training. Data are mean \pm SEM. Different letters indicated significant difference at $P<0.05$ by one-way ANOVA. 
In addition, Fig. 3 and 4 also showed that exercise training increased capillary density with neocapillarization in the gastrocnemius and soleus muscles. Angiogenesis induced by exercise has been reported to cooperate with increasing expression of angiogenic factors [22]. Lloyd et al. [23] showed that the treadmill exercise training induced angiogenesis in the gastrocnemius muscles, which might be related with activation of angiopoietin and VEGF. Iemitsu et al. [24] also exhibited that the swimming exercise training improved aging-induced reduction of cardiac capillary density, and a decrease in expression of VEGF and its receptors, Flt-1 and Flk-1, in the heart.

\section{Effect of exercise training on SIRT1, PGC-1a, AMPK and FOXO3a}

Fig. 5 showed a representative western blot of SIRT1, PGC-1a, AMPK and FOXO3a levels in the gastrocnemius muscles. The SIRT1 of the gastrocnemius muscles in the $3 \mathrm{ME}$ and $12 \mathrm{ME}$ groups with the ratios of $1.27 \pm 0.16$ and $1.70 \pm 0.34$ showed slightly increased by $27 \%$ and $23 \%$, respectively, relative to those observed in $3 \mathrm{MC}$ group $(1.00 \pm 0.25)$ and $12 \mathrm{MC}$ group $(1.38 \pm 0.19)$. The groups of $3 \mathrm{ME}$ $(1.05 \pm 0.07), 12 \mathrm{ME}(1.34 \pm 0.63)$ and $18 \mathrm{ME}(1.64 \pm 0.21)$ had increased the gastrocnemius PGC-1a levels by $5 \%, 38 \%$ and $48 \%(P<0.05)$, respectively, relative to those observed in 3MC $(1.00 \pm 0.13), 12 \mathrm{MC}(0.98 \pm$ $0.27)$ and $18 \mathrm{MC}(1.11 \pm 0.13)$ groups. The FOXO3a level of the gastrocnemius muscles in 3ME group (1.30 \pm 0.16 ) was slightly increased by $30 \%$ than $3 \mathrm{MC}$ group $(1.00 \pm 0.26)$, and the groups of $12 \mathrm{ME}(2.15 \pm 0.28)$ and 18ME (1.27 \pm 0.11$)$ had significantly increased FOXO3a levels by $62 \%$ and $66 \%(P<0.05)$, respectively, relative to those observed in 12MC (1.33 $\pm 0.44)$ and $18 \mathrm{MC}(0.77 \pm 0.22)$ groups. The AMPK of the gastrocnemius muscles in the $3 \mathrm{ME}, 12 \mathrm{ME}$ and $18 \mathrm{ME}$ groups showed slightly increased by $62 \%, 14 \%$ and $74 \%$, respectively, relative to those observed in $3 \mathrm{MC}, 12 \mathrm{MC}$ and $18 \mathrm{MC}$ groups. But there was no significant difference among each group in the AMPK levels of the gastrocnemius muscles. There was a significant main effect of exercise on PGC-1a ( $P=$ $0.0088)$ and FOXO3a $(P<0.0001)$ in the gastrocnemius muscles, but there was no effect of exercise on SIRT1 $(P=0.1052)$ and AMPK $(P=0.1494)$. Calculated SIRT1 $(P=0.0005)$, PGC-1a $(P=0.0446)$ and FOXO3a $(P<$ $0.0001)$ have significant difference on different ages, but AMPK $(P=0.7084)$ did not differ among different ages. There was no significant interaction (age $\times$ exercise) for SIRT1 $(P=0.1191)$, PGC-1a $(P=0.1897)$, AMPK $(P=0.7527)$ and FOXO3a $(P=0.0926)$ (Table 2).

Table 2. Effect of age and exercise training on SIRTI, PGC-1a, AMPK and FOXO3a.

\begin{tabular}{|c|c|c|c|c|c|}
\hline Group & 3-month-old & 12-month-old & 18-month-old & Effect & $P$ \\
\hline SIRT1 of gastrocnemius & & & & Age & 0.0005 \\
\hline Sedentary & $1.00 \pm 0.10$ & $1.38 \pm 0.08$ & $1.79 \pm 0.17$ & Exercise & 0.1052 \\
\hline Swimming exercise training & $1.27 \pm 0.07$ & $1.70 \pm 0.14$ & $1.67 \pm 0.02$ & Age $x$ Exercise & 0.1191 \\
\hline PGC-1 $\alpha$ of gastrocnemius & & & & Age & 0.0446 \\
\hline Sedentary & $1.00 \pm 0.05$ & $0.98 \pm 0.11$ & $1.11 \pm 0.05$ & Exercise & 0.0088 \\
\hline Swimming exercise training & $1.05 \pm 0.03$ & $1.34 \pm 0.26$ & $1.64 \pm 0.09$ & Age $x$ Exercise & 0.1897 \\
\hline AMPK of gastrocnemius & & & & Age & 0.7084 \\
\hline Sedentary & $1.00 \pm 0.19$ & $0.99 \pm 0.17$ & $0.77 \pm 0.06$ & Exercise & 0.1494 \\
\hline Swimming exercise training & $1.62 \pm 0.60$ & $1.13 \pm 0.13$ & $1.34 \pm 0.54$ & Age $x$ Exercise & 0.7527 \\
\hline FOXO3a of gastrocnemius & & & & Age & $<0.0001$ \\
\hline Sedentary & $1.00 \pm 0.11$ & $1.33 \pm 0.18$ & $0.77 \pm 0.09$ & Exercise & $<0.0001$ \\
\hline Swimming exercise training & $1.30 \pm 0.07$ & $2.15 \pm 0.11$ & $1.27 \pm 0.05$ & Age $x$ Exercise & 0.0926 \\
\hline SIRT1 of soleus & & & & Age & 0.0023 \\
\hline Sedentary & $1.00 \pm 0.01$ & $1.42 \pm 0.07$ & $1.75 \pm 0.15$ & Exercise & 0.0081 \\
\hline Swimming exercise training & $1.45 \pm 0.05$ & $1.85 \pm 0.20$ & $1.92 \pm 0.20$ & Age $x$ Exercise & 0.5521 \\
\hline PGC-1 $\alpha$ of soleus & & & & Age & 0.2001 \\
\hline Sedentary & $1.00 \pm 0.04$ & $1.07 \pm 0.10$ & $0.91 \pm 0.01$ & Exercise & 0.0029 \\
\hline Swimming exercise training & $1.04 \pm 0.00$ & $1.20 \pm 0.07$ & $1.30 \pm 0.08$ & Age $x$ Exercise & 0.0391 \\
\hline AMPK of soleus & & & & Age & 0.1422 \\
\hline Sedentary & $1.00 \pm 0.02$ & $1.37 \pm 0.25$ & $1.07 \pm 0.02$ & Exercise & 0.0496 \\
\hline Swimming exercise training & $1.56 \pm 0.12$ & $1.35 \pm 0.07$ & $1.16 \pm 0.02$ & Age $x$ Exercise & 0.0657 \\
\hline FOXO3a of soleus & & & & Age & 0.1770 \\
\hline Sedentary & $1.00 \pm 0.05$ & $1.71 \pm 0.17$ & $1.08 \pm 0.10$ & Exercise & 0.2693 \\
\hline Swimming exercise training & $1.38 \pm 0.44$ & $1.00 \pm 0.08$ & $0.84 \pm 0.02$ & Age $x$ Exercise & 0.0534 \\
\hline
\end{tabular}

Data are mean \pm SEM. 

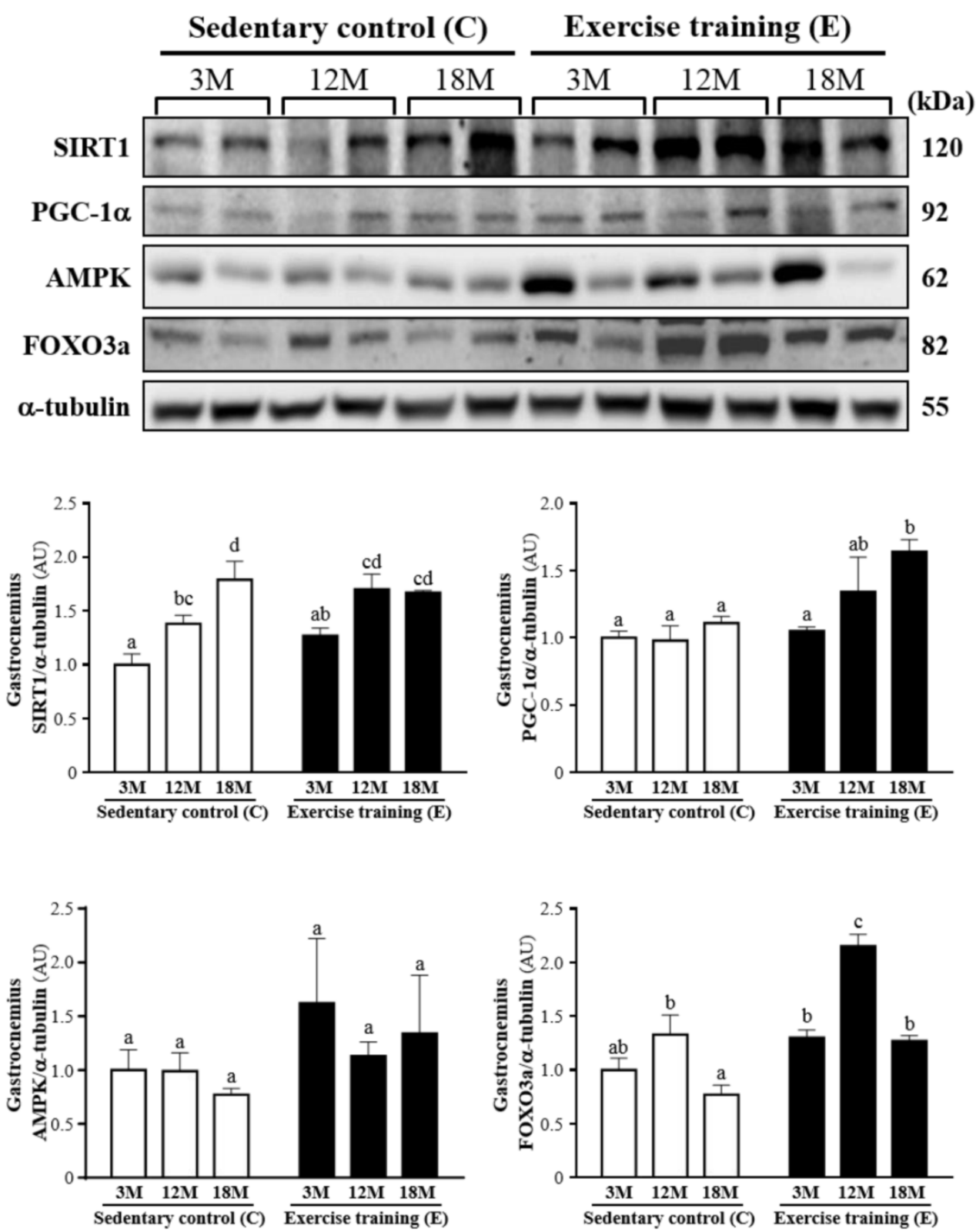

Figure 5 Protein expression levels of SIRT1, PGC-1 $\alpha$, AMPK and FOXO3a in the gastrocnemius muscles as measured by Western blot. $\alpha$-tubulin was used an internal control. Data were expressed as mean \pm SEM of eight rats. 3MC; male 3-month-old SD rats without swimming exercise training, 3ME; male 3-month-old SD rats with swimming exercise training, 12MC; male 12-month-old SD rats without swimming exercise training, 12ME; male 12-month-old SD rats with swimming exercise training, 18MC; male 18-month-old SD rats without swimming exercise training, 18ME; male 18-month-old SD rats with swimming exercise training. Different letters indicated significant difference at $P<0.05$ by one-way ANOVA.

The western blot of SIRT1, PGC-1a, AMPK and FOXO3a levels in the soleus muscles was shown in Fig. 6. SIRT1 was significantly increased by $45 \%(P<$ $0.05), 30 \%(P<0.05)$ and $10 \%$, respectively, in $3 \mathrm{ME}$ group (1.45 \pm 0.13$)$, $12 \mathrm{ME}$ group $(1.85 \pm 0.48)$ and $18 \mathrm{ME}$ group $(1.92 \pm 0.50)$ when compared with $3 \mathrm{MC}$ group $(1.00 \pm 0.02), 12 \mathrm{MC}$ group $(1.42 \pm 0.18)$ and $18 \mathrm{MC}$ group $(1.75 \pm 0.36)$. And PGC-1a was increased by $4 \%, 13 \%$ and $43 \%(P<0.05)$, respectively, in the $3 \mathrm{ME}$ group (1.04 \pm 0.13$), 12 \mathrm{ME}$ group $(1.20 \pm 0.17)$ and $18 \mathrm{ME}$ group $(1.30 \pm 0.20)$ when compared with $3 \mathrm{MC}$ group $(1.00 \pm 0.10), 12 \mathrm{MC}$ group $(1.07 \pm 0.25)$ and
18MC group $(0.91 \pm 0.03)(P<0.05)$. It is interesting, the FOXO3a levels of the soleus muscles in the 12MC group $(1.71 \pm 0.41)$ were significantly higher than 12ME group $(1.00 \pm 0.19)(P<0.05)$. The AMPK level of the soleus muscles in the 3ME group $(1.56 \pm 0.29)$ was significantly increased by $56 \%$ than $3 \mathrm{MC}$ group $(1.00 \pm 0.06)(P<0.05)$. By directly observing SIRT1, PGC-1a, AMPK and FOXO3a levels in 3-, 12- and 18-month-old rats with and without exercise, there was a significant main effect of exercise on SIRT1 $(P=$ $0.0081)$, PGC-1a $(P=0.0029)$ and AMPK $(P=0.0496)$ in the soleus muscles. Calculated SIRT1 $(P=0.0023)$ 
has significant difference on different ages, but PGC-1a $(P=0.2001), \operatorname{AMPK}(P=0.1422)$ and FOXO3a $(P=0.1770)$ did not differ among different ages. There was no significantly interaction (age $\times$ exercise) for SIRT1 $(P=0.5521)$, AMPK $(P=0.0657)$ and FOXO3a $(P$ $=0.0534)$, but there was significantly interaction (age $\times$ exercise) for PGC-1a $(P=0.0391)$.

\section{Comment}

We conducted a series of experiments to characterize the effects of swim exercise training and age on SIRT1, PGC-1 $\alpha$, AMPK and FOXO3a. The major findings were that (i) $40 \mathrm{~min} / \mathrm{d}$ of swim exercise significantly decreased body weight in 18-month-old rats, but not in 3- and 12-month-old rats; (ii) $40 \mathrm{~min} / \mathrm{d}$ of swim exercise significantly increased fiber length and area of the gastrocnemius and soleus muscles, regardless of age; and (iii) rats with exercise compared to rats without exercise at the same age consistently had higher protein expressions of SIRT1, PGC-1a and AMPK in the gastrocnemius and soleus muscles.
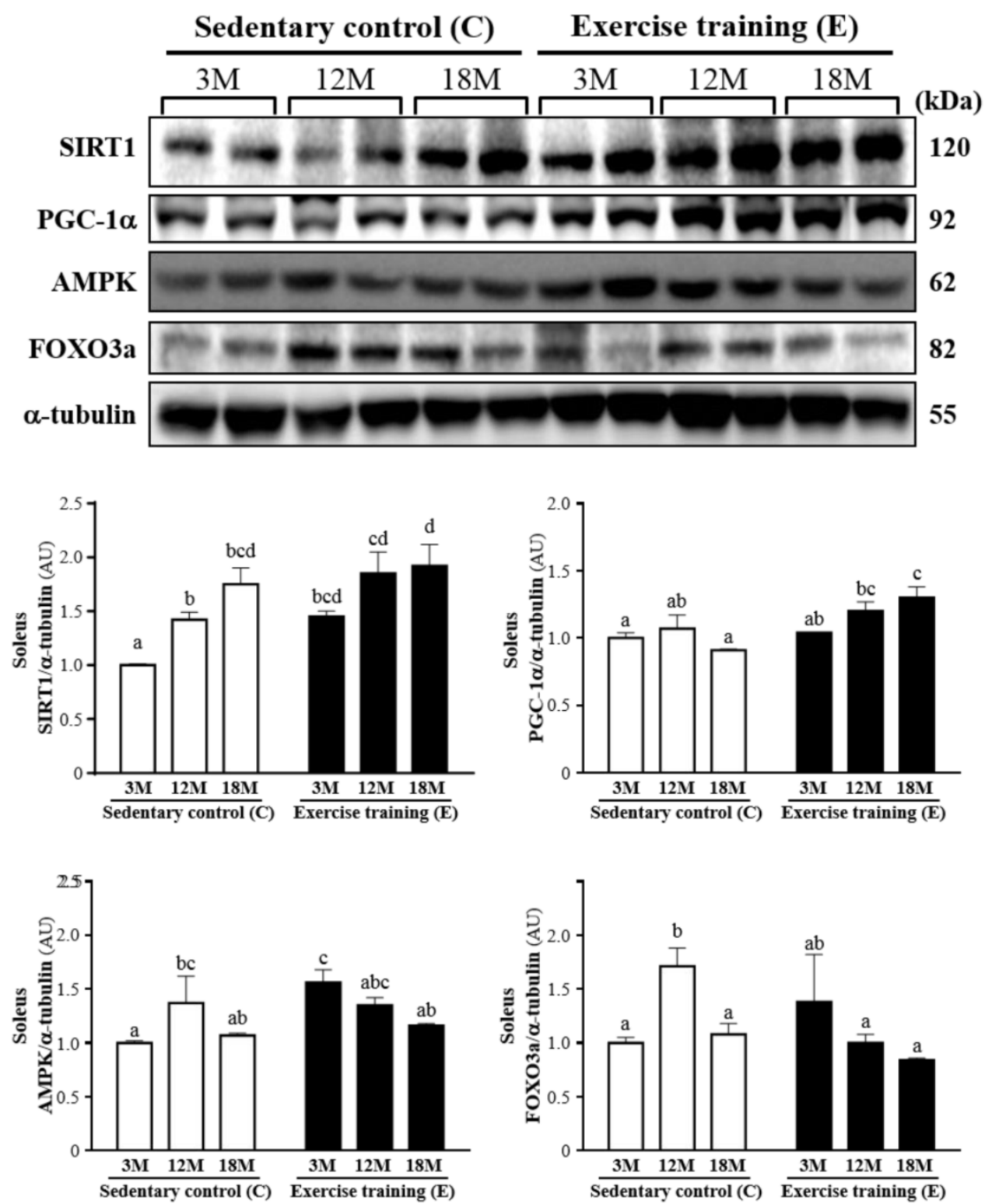

Figure 6 Protein expression levels of SIRT1, PGC-1 $\alpha$, AMPK and FOXO3a in the soleus muscles as measured by Western blot. $\alpha$-tubulin was used an internal control. Data were expressed as mean \pm SEM of eight rats. 3MC; male 3-month-old SD rats without swimming exercise training, 3ME; male 3-month-old SD rats with swimming exercise training, 12MC; male 12-month-old SD rats without swimming exercise training, 12ME; male 12-month-old SD rats with swimming exercise training, 18MC; male 18-month-old SD rats without swimming exercise training, 18ME; male 18-month-old SD rats with swimming exercise training. Different letters indicated significant difference at $P<0.05$ by one-way ANOVA. 
The SIRT1 of the gastrocnemius/soleus muscles in the exercise training groups showed increased when compared with the sedentary groups at 3-month- and 12-month-aged rats, except for 18-month-aged rats. These results showed that exercise has been considered a positive regulator in controlling SIRT1 expression at different age rats. In agreement with Falone et al. [25], exercise training enhances human SIRT1 expression in the hippocampus. SIRT1, which regulates diverse biological processes ranging from DNA repair and genome stability to glucose and lipid homeostasis, is an essential mediator of longevity in normal cells [26]. SIRT1 also plays a vital role in cellular physiological processes, including metabolism, and cell degeneration, growth and survival, and participates in an important function in regulating inflammation, such as the mitogen-activated protein kinase family (MAPKs) and NF-kB [27-29].

$3 \mathrm{ME}, 12 \mathrm{ME}$ and $18 \mathrm{ME}$ groups had increased the gastrocnemius/soleus muscles PGC-1a levels by $5 \% / 4 \%, 38 \% / 13 \%$ and $48 \% / 43 \%$, respectively, relative to those observed in $3 \mathrm{MC}$ group, $12 \mathrm{MC}$ group and $18 \mathrm{MC}$ group. In agreement with previous studies, The mRNA and protein expression of PGC-1a were significantly increased by acute endurance exercise [30-33] and endurance exercise training [34, 35], thus suggesting that PGC-1a was a possible regulator of metabolic adaptations with endurance exercise.

The AMPK levels of gastrocnemius in the $3 \mathrm{ME}$, $12 \mathrm{ME}$ and 18ME significantly increased by $62 \%, 14 \%$ and $74 \%$, respectively, relative to those observed in $3 \mathrm{MC}$ group, $12 \mathrm{MC}$ group and $18 \mathrm{MC}$ group. In this study, we found that activation of AMPK may positively regulate SIRT1 and PGC-1a expression in muscles, thereby improving movement performance. Lezi et al. [36] exhibited that exercise training had higher SIRT1, PGC-1 and AMPK proteins in the liver and brain [36]. Both AMPK and p38 MAPK in muscle were activated by contractile activity and endurance exercise [37-41]. Collectively, these results increase the possibility that the metabolic adaptations resulting from endurance exercise training result at least in part via an increased PGC-1a protein through the AMPK and p38 MAPK pathways [42].

The FOXO3a levels of gastrocnemius in 12ME and $18 \mathrm{ME}$ groups were significantly increased than $12 \mathrm{MC}$ and $18 \mathrm{MC}$ groups, but the FOXO3a level of the soleus muscles in the $12 \mathrm{MC}$ group was significantly higher than 12ME group. Moreover, SIRT1 regulates longevity factors and several factors by deacetylation of FOXO family [43], SIRT1 regulates age-related changes in different mechanisms including increasing mitochondriogenesis by modulating PGC-1a deacetylation, repressing oxidative stress survival response by FOXO family, reducing apoptosis and proliferation caused by p53 deacetylation and mitigating pro-inflammatory response by NF-кB activation $[44,45]$.

SIRT1, PGC-1a, AMPK and FOXO3a levels in 3-, 12- and 18-month-old rats with and without exercise, there was a significant main effect of exercise on PGC-1a, AMPK and FOXO3a in gastrocnemius muscles, and SIRT1, PGC-1a and AMPK in the soleus muscles. SIRT1 functionally deacetylates and activates PGC-1a [46, 47]. SIRT1 is a key regulator of mitochondrial biogenesis through the deacetylation of PGC-1a in skeletal muscle cells [46, 48]. SIRT1 plays a vital role in the modulation of the cytosolic $\mathrm{NAD}^{+} / \mathrm{NADH}$ ratio in muscle gene expression [49]. SIRT1 contributes to skeletal muscle adaptations with endurance exercise that may be due to the cytosolic $\mathrm{NAD}^{+} / \mathrm{NADH}$ ratio changes during muscle contraction [50]. Suwa et al. [42] therefore showed that SIRT1 has increased after endurance exercise to facilitate such metabolic adaptation. Palacios et al. [17] also showed that in the beginning of energy stress, AMPK acts as a sensor to allow the cell to interact efficiently with different energetic substrates. Hence, activation of SIRT1 involves the metabolic and transcriptional rearrangements which is an indirect sequence induced by AMPK activation. In addition to the ability to regulate Nampt expression, AMPK may also affect intracellular NAD+ levels, which further modulate SIRT1 downstream targets such as PGC-1a and FOXO1. Consequently, SIRT1 activation constitutes an indirect consequence of the metabolic and transcriptional rearrangements induced by AMPK activation.

In conclusion, the present study demonstrated that swimming exercise training at $40 \mathrm{~min} / \mathrm{d}$ for 12 weeks can attenuate fiber size of muscles results in regulate the SIRT1, PGC- $1 \alpha$, AMPK and FOXO3a in muscles of different age rats. Therefore, the SIRT1/PGC-1 $\alpha$ pathway can directly regulate the biophysiological functions of skeletal muscle.

\section{Acknowledgments}

This study was supported by the Ministry of Science and Technology of Taiwan (grants no. NSC-99-2410-H029-059-MY2 and MOST-103-2410-H029-037 to Wan-Teng Lin). The authors are grateful to Miss Kai-Wen Chang and Dr. Wen-Ching Huang for technical assistance in animal experiments.

\section{Competing Interests}

The authors declare no competing interest. 


\section{References}

1. De Angelis K, Schaan BD, Maeda CY, Dall'Ago P, Wichi RB, Irigoyen MC. Cardiovascular control in experimental diabetes. Braz J Med Biol Res. 2002; 35:1091-1100.

2. Ghosh S, Pulinilkunnil T, Yuen G, Kewalramani G, An D, Oi D, Abrahani A, Rodrigues B. Cardiomyocyte apoptosis induced by short-term diabetes requires mitochondrial GSH depletion. Am J Physiol Heart Circ Physiol. 2005; 289:H768-H776

3. Hu FB, Manson JE, Stampfer MJ, Colditz G, Liu S, Solomon CG, Willett WC. Diet, lifestyle, and the risk of type 2 diabetes mellitus in women. N Engl J Med. 2001; 345:790-797.

4. Anitha V, Asha Devi S. Age-related responses of right ventricle in swim-trained rats: changes in lactate and pyruvate contents and lactate dehydrogenase activity. Mech Ageing Dev. 1996; 90:91-102.

5. Stampfer MJ, Hu FB, Manson JE, Rimm EB, Willett WC. Primary prevention of coronary heart disease in women through diet and lifestyle. N Engl J Med. 2000; 343:16-22.

6. Tan N, Morimoto K, Sugiura T, Morimoto A, Murakami N. The effects of running training on the blood glucose and lactate in rats during rest and swimming. Phvsiol Behav. 1992; 51:927-931.

7. Bhagavathi R, Devi SA. Interaction of exercise and age on substrates of carbohydrate metabolism. Indian J Esp Biol. 1993; 31:72-75.

8. Kramer K, Dijkstra H, Bast A. Control of physical exercise of rats in a swimming basin. Physiol Behav. 1993; 53:271-276.

9. Ravi Kiran T, Subramanyam MV, Asha Devi S. Swim exercise training and adaptations in the antioxidant defense system of myocardium of old rats: relationship to swim intensity and duration. Comp. Biochem Physiol B Biochem Mol Biol. 2004; 137:187-196.

10. Frazzi R, Valli R, Tamagnini I, Casali B, Latruffe N, Merli F. Resveratrol-mediated apoptosis of Hodgkin lymphoma cells involves SIRT1 inhibition and FOXO3a hyperacetylation. Int J Cancer. 2013; 132:1013-1021.

11. Lakshminarasimhan $M$, Rauth D, Schutkowski M, Steegborn C. Sirt1 activation by resveratrol is substrate sequenceselective. Aging (Albany NY). 2013; 5:151-154

12. Li T, Zhang J, Feng J, Li Q, Wu L, Ye Q, Sun J, Lin Y, Zhang M, Huang R, Cheng J, Cao Y, Xiang G, Zhang J, Wu Q. Resveratrol reduces acute lung injury in a LPS? Induced sepsis mouse model via activation of Sirt1. Mol Med Rep. 2013; 7:1889-1895

13. Oellerich MF, Potente M. FOXOs and sirtuins in vascular growth, maintenance, and aging. Circ Res. 2012; 110:1238-1251.

14. Zarzuelo MJ, López-Sepúlveda R, Sánchez M, Romero M, Gómez-Guzmán M, Ungvary Z, Pérez-Vizcaíno F, Jiménez R, Duarte J. SIRT1 inhibits NADPH oxidase activation and protects endothelial function in the rat aorta: implications for vascular aging. Biochem Pharmacol. 2013; 85:1288-1296.

15. Ferrer MD, Tauler P, Sureda A, Tur JA, Pons A. Antioxidant regulatory mechanisms in neutrophils and lymphocytes after intense exercise. J Sports Sci. 2009; 27:49-58.

16. Lanza IR, Short DK, Short KR, Raghavakaimal S, Basu R, Joyner MJ, McConnell JP, Nair KS. Endurance exercise as a countermeasure for aging. Diabetes. 2008; 57:2933-2942.

17. Palacios OM, Carmona JJ, Michan S, Chen KY, Manabe Y, Ward JL 3rd, Goodyear LJ, Tong Q. Diet and exercise signals regulate SIRT3 and activate AMPK and PGC-1a in skeletal muscle. Aging (Albany NY). 2009; 1:771-783.

18. Oscai LB, Spirakis CN, Wolff CA, Beck RJ. Effects of exercise and of food restriction on adipose tissue cellularity. J Lipid Res. 1972; 13:588-592.

19. Hirsch J, Han PW. Cellularity of rat adipose tissue: effects of growth, starvation, and obesity. J Lipid Res. 1969; 10:77-82.

20. Johnson PR, Zucker LM, Cruce JA, Hirsch J. Cellularity of adipose depots in the genetically obese Zucker rat. J Lipid Res. 1971; 12:706-714.

21. Kraemer WJ, Fleck SJ, Evans WJ. Strength and power training: physiological mechanisms of adaptation. In: Exercise and Sport Sciences Reviews, edited by Holloszy JO, Baltimore MD. Williams andWilkins. 1996: 363-397.

22. Viboolvorakul S, Niimi H, Wongeak-in N, Eksakulkla S, Patumraj S. Increased capillary vascularity in the femur of aged rats by exercise training. Microvasc Res. 2009; 78:459-463.

23. Lloyd PG, Prior BM, Yang HT, Terjung RL. Angiogenic growth factor expression in rat skeletal muscle in response to exercise training. Am J Physiol Heart Circ Physiol. 2003; 284:H1668-H1678.

24. Iemitsu M, Maeda S, Jesmin S, Otsuki T, Miyauchi T. Exercise training improves aging-induced downregulation of VEGF angiogenic signaling cascade in hearts. Am J Physiol Heart Circ Physiol. 2006; 291:H1290-H1298.

25. Falone S, D'Alessandro A, Mirabilio A, Cacchio M, Di Ilio C, Di Loreto S, Amicarelli F. Late-onset running biphasically improves redox balance, energyand methylglyoxal-related status, as well as SIRT1 expression in mouse hippocampus. PLoS One. 2012; 7:e48334

26. Moreau M, Neveu M, Stéphan S, Noblesse E, Nizard C, Sadick NS, Schnebert $\mathrm{S}$, Bonté F, Dumas M, Andre P, Perrier E. Enhancing cell longevity for cosmetic application: a complementary approach. J Drugs Dermatol. 2007; 6: s14-s19.

27. Sauve AA, Wolberger C, Schramm VL, Boeke JD. The biochemistry of sirtuins. Annu Rev Biochem. 2006; 75:435-465.

28. Milne JC, Denu JM. The Sirtuin family: therapeutic targets to treat diseases of aging. Curr Opin Chem Biol. 2008; 12:11-17.

29. Yoshizaki T, Schenk S, Imamura T, Babendure JL, Sonoda N, Bae EJ, Oh DY, Lu M, Milne JC, Westphal C, Bandyopadhyay G, Olefsky JM. SIRT1 inhibits inflammatory pathways in macrophages and modulates insulin sensitivity. Am J Physiol Endocrinol Metab. 2010; 298:E419-E428.

30. Baar K, Wende AR, Jones TE, Marison M, Nolte LA, Chen M, Kelly DP, Holloszy JO. Adaptations of skeletal muscle to exercise: rapid increase in the transcriptional coactivator PGC-1. FASEB J. 2002; 16:1879-1886.

31. Pilegaard H, Saltin B, Neufer PD. Exercise induces transient transcriptional activation of the PGC-1a gene in human skeletal muscle. J Physiol. 2003; 546:851-858.

32. Terada S, Goto M, Kato M, Kawanaka K, Shimokawa T, Tabata I. Effects of low-intensity prolonged exercise on PGC-1 mRNA expression in rat epitrochlearis muscle. Biochem Biophys Res Commun. 2002; 296:350-354.

33. Terada S, Tabata I. Effects of acute bouts of running and swimming exercise on PGC-1a protein expression in rat epitrochlearis and soleus muscle. Am J Physiol Endocrinol Metab. 2004; 286:E208-216.

34. Russell AP, Feilchenfeldt J, Schreiber S, Praz M, Crettenand A, Gobelet C, Meier CA, Bell DR, Kralli A, Giacobino JP, Dériaz O. Endurance training in humans leads to fiber type-specific increases in levels of peroxisome proliferator-activated receptor- $\gamma$ coactivator-1 and peroxisome proliferator-activated receptor- $\alpha$ in skeletal muscle. Diabetes. 2003; 52:2874-2881.

35. Taylor EB, Lamb JD, Hurst RW, Chesser DG, Ellingson WJ, Greenwood LJ, Porter BB, Herway ST, Winder WW. Endurance training increases skeletal muscle LKB1 and PGC-1 protein abundance: effects of time and intensity. Am J Physiol Endocrinol Metab. 2005; 289:E960-968.

36. Lezi E, Lu J, Burns JM, Swerdlow RH. Effect of exercise on mouse liver and brain bioenergetic infrastructures. Exp Physiol. 2013; 98:207-219.

37. Akimoto T, Pohnert SC, Li P, Zhang M, Gumbs C, Rosenberg PB, Williams RS, Yan Z. Exercise stimulates Pgc-1a transcription in skeletal muscle through activation of the p38 MAPK pathway. J Biol Chem. 2005; 280:19587-19593.

38. Chen ZP, Stephens TJ, Murthy S, Canny BJ, Hargreaves M, Witters LA, Kemp BE, McConell GK. Effect of exercise intensity on skeletal muscle AMPK signaling in humans. Diabetes. 2003; 52:2205-2212.

39. Fujii N, Hayashi T, Hirshman MF, Smith JT, Habinowski SA, Kaijser L, Mu J, Ljungqvist O, Birnbaum MJ, Witters LA, Thorell A, Goodyear LJ. Exercise induces isoformspecific increase in $5^{\prime} \mathrm{AMP}$-activated protein kinase activity in human skeletal muscle. Biochem Biophys Res Commun. 2000; 273:1150-1155.

40. Irrcher I, Adhihetty PJ, Sheehan T, Joseph AM, Hood DA. PPARY coactivator-1a expression during thyroid hormone- and contractile activity-induced mitochondrial adaptations. Am J Physiol Cell Physiol. 2003; 284:C1669-1677.

41. Boppart MD, Asp S, Wojtaszewski JF, Fielding RA, Mohr T, Goodyear LJ. Marathon running transiently increases c-Jun $\mathrm{NH}_{2}$-terminal kinase and p38 activities in human skeletal muscle. J Physiol. 2000; 526:663-669.

42. Suwa M, Nakano H, Radak Z, Kumagai S. Endurance exercise increases the SIRT1 and peroxisome proliferator-activated receptor $\gamma$ coactivator-1a protein expressions in rat skeletal muscle. Metabolism. 2008; 57:986-998.

43. Salminen A, Kaarniranta K. Insulin/IGF-1 paradox of aging: regulation via AKT/IKK/NF-KB signaling. Cell Signal. 2010; 22:573-577.

44. Yeung F, Hoberg JE, Ramsey CS, Keller MD, Jones DR, Frye RA, Mayo MW. Modulation of NF-KB-dependent transcription and cell survival by the SIRT1 deacetylase. EMBO J. 2004; 23:2369-2380.

45. Lavu S, Boss O, Elliott PJ, Lambert PD. Sirtuins - novel therapeutic targets to treat age-associated diseases. Nat Rev Drug Discov. 2008; 7:841-853.

46. Lagouge M, Argmann C, Gerhart-Hines Z, Meziane H, Lerin C, Daussin F, Messadeq N, Milne J, Lambert P, Elliott P, Geny B, Laakso M, Puigserver P, Auwerx J. Resveratrol improves mitochondrial function and protects against metabolic disease by activating SIRT1 and PGC-1a. Cell. 2006; 127:1109-1122.

47. Rodgers JT, Lerin C, Haas W, Gygi SP, Spiegelman BM, Puigserver P. Nutrient control of glucose homeostasis through a complex of PGC-1a and SIRT1. Nature. 2005; 434:113-118.

48. Gerhart-Hines Z, Rodgers JT, Bare O, Lerin C, Kim SH, Mostoslavsky R, Alt FW, Wu Z, Puigserver P. Metabolic control of muscle mitochondrial function and fatty acid oxidation through SIRT1/PGC-1a. EMBO J. 2007; 26:1913-1923.

49. Fulco M, Schiltz RL, Iezzi S, King MT, Zhao P, Kashiwaya Y, Hoffman E, Veech RL, Sartorelli V. Sir2 regulates skeletal muscle differentiation as a potential sensor of the redox state. Mol Cell. 2003; 12:51-62.

50. Robergs RA, Ghiasvand F, Parker D. Biochemistry of exercise-induced metabolic acidosis. Am J Physiol Regul Integr Comp Physiol. 2004; 287:R502-516. 